\title{
Research of the dependence of pneumatic conveyor compressors power on project parameters of transport machines
}

\author{
Sergij Raksha ${ }^{1}$, Vladimir Bohomaz ${ }^{1, *}$, Igor Shcheka ${ }^{1}$, Volodymyr Stefanov ${ }^{2}$, and Alex \\ Nesterenko ${ }^{3}$ \\ ${ }^{1}$ Department of Applied Mechanics and Materials Science, Dnipropetrovsk National University of \\ Railway Transport named after Academician V. Lazaryan, Lazaryan St., 2, Dnipro, Ukraine \\ ${ }^{2}$ Department of Construction, track and handling machines, Ukrainian State University of Railway \\ Transport, Feierbakh Square 7, 61050, Kharkiv, Ukraine \\ ${ }^{3}$ National Academy of the National Guard of Ukraine, Defenders of Ukraine sq. 3, 61001, Kharkiv, \\ Ukraine
}

\begin{abstract}
The paper considers the algorithm for calculating the pneumatic transport systems of the main constructions: with high vacuum and with different pressures. The analysis of the dependence of all calculation elements on the design data of the transport system of the considered structures was carried out. In order to accelerate the calculation of such systems, the analytical dependence of the power of the compressor drive on the type of cargo, the coefficient of concentration of the transported mixture, the design productivity, and the geometric parameters of the route, the number and types of auxiliary devices (ells and shutters) are constructed. A graphical analysis of the dependence of compressor drive power of the pneumatic transport systems with high vacuum and with different pressures on the design data: the mixture concentration coefficient, the length of transportation, the design productivity for the transportation of cement with a given route configuration. The directions for further research have been determined.
\end{abstract}

\section{Introduction}

Pneumatic transport systems are very widely used in various industries, in construction, in transshipment work on rail and water transport. The load is transported through pipes and troughs due to the energy of the air flow in such systems. The main types of cargo that are transported by pneumatic conveyors are cement, mineral powders, crushed rock, ash and slag, chips and other types of goods.

The advantages of pneumatic conveyors in comparison with other transport vehicles include: tightness of the system; absence of the losses of transportable cargo; the convenience of conjugation of horizontal, vertical and inclined sections; the concentration of machine equipment in one place and the lack of need for complex maintenance throughout the route; the ability to move loads from several places to one and vice versa;

\footnotetext{
* Corresponding author: wbogomas@i.ua
} 
the possibility of combining transport with several technological processes, such as cooling and drying.

One of the main elements of pneumatic systems is a compressor which is driven by an electric motor. Consequently, one of the important technical parameters of the pneumatic plant is the power of the drive of the compressor or blower machine.

The power of the compressor drive of a pneumatic transport installation depends on many factors. The main parameters influencing its value are: the cargo and its density; productivity of the plant for the cargo; horizontal and vertical dimensions of the transportation route; the number and types of auxiliary devices (ells and shutters); the given coefficient of the mixtures concentration.

\section{Analysis of recent research and publications}

The main publications describing the structure, design features, operational and design parameters of the modern machines of continuous transport are [1-8]. The analysis of publications shows that in order to determine the parameters of the drive of the compressor of the pneumatic transport unit, in particular its capacity, it is necessary to carry out a detailed calculation, namely: speed of air mixture (critical and actual), total pressure losses in the pneumatic system, air flow at the outlet of the compressor, working of the compressor and power drive compressor. The procedure for conducting such calculations is described in detail in the papers $[1-4,8]$. Consequently, in order to accelerate the process of designing pneumatic transport units, it is necessary to construct a formula for determining the power of the compressor drive, which considers all output design data of the machine. There are papers in which the reduced algorithms for calculating the magnitude of the power of the drive of continuous transport vehicles are presented. In the paper [9] the authors constructed an algorithm for accelerated calculation of the belt elevator power with given design characteristics. The paper [10] is devoted to the construction of the dependence of the belt conveyors capacity on its design values.

\section{Determine the purpose and objectives of the research}

The purpose of the work is a graphical analysis of the dependence of the power of the compressor drive pneumatic transport units on the design productivity, type of cargo, the ratio of the mixture concentration and the length of the cargo transportation. For analysis, the task of the research is to construct an analytical dependence of the compressor drive power on the above design characteristics.

\section{The main part of the research}

The initial data for designing pneumatic transport machines are: the type of cargo and its density $\rho_{c}$; the air density $\rho_{a}$; the productivity of machine $T_{c}$; the length of the transportation route $L$; the lifting height $H$; the coefficient of the mixtures concentration $\mu$; the number of the ells and shutters of the track.

The schemes of pneumatic transport machines are imagined in fig. 1.

The pneumatic transport machines, depending on the value of the mixture concentration ratio, are aspiration $(\mu \leq 1)$, with high vacuum $(\mu=1 \ldots 5)$, pumping $(\mu=8 \ldots 25)$.

For a further analysis of the dependence of all elements of the calculation from the initial design data, we present a general algorithm for calculating the pneumatic transport unit [2]. 
The weight productivity of the pneumatic machine by air:

$$
T_{a}=\frac{T_{c}}{3.6 \mu} .
$$

The volume productivity of the pneumatic machine by air:

$$
V_{a}=\frac{T_{c}}{3.6 \mu \rho_{a}} .
$$

The productivity of the pneumatic machine by air and the cargo:

$$
V=V_{c}+V_{a}
$$

The diameter of the pipeline is taken $d_{\mathrm{p}}$.

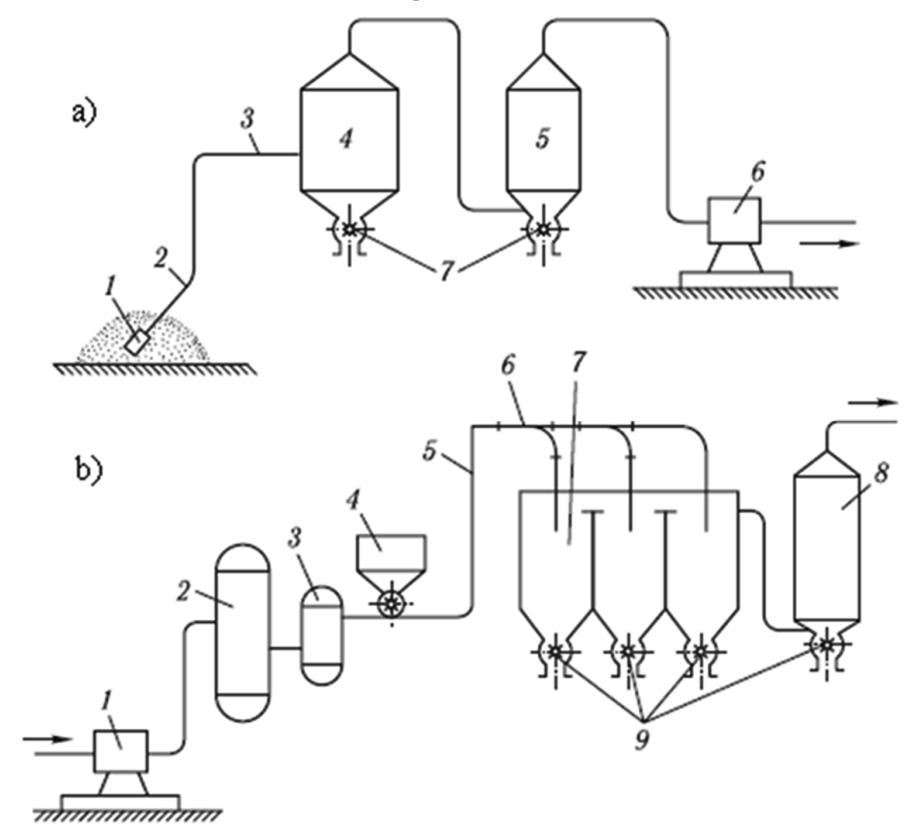

Fig. 1. The schemes of pneumatic transport machines: a) - suction machine $(1$ - nozzle; 2 - flexible pipeline; 3 - rigid pipeline; 4 - separator; 5 - filters; 6 - vacuum pump; 7 - locking ells); b) - pressure machine (1 compressor; 2 air sampler ; 3 - water separator; 4 - a loading device; 5 - a pipeline; 6 - two-way switch; 7 - separator; 8 - filters; 9 - locking ells)

The critical speed of the air mixture:

$$
v_{c r}=n_{2} \sqrt{\mu a g d_{p}},
$$

where $n_{2}$ - the experimental constant; $n_{2}=0.1$ - for dusty, easy-to-handle cargoes; $n_{2} \leq 0.25$ for dusty cargoes that are prone to felling; $n_{2} \leq 0.3$ - for granular cargoes; $n_{2} \leq 0.35$ - for lump cargo; in our calculations we accept $n_{2}=0.1$.

The coefficient $a$ is found on the formula: 


$$
a=\frac{\rho_{c}-\rho_{a}}{\rho_{a}} .
$$

The speed of the air mixture in the pipeline:

$$
v_{m}=\frac{4 V}{3600 \pi d_{p}^{2}} .
$$

For the normal working of the machine, the speed of the air mixture in the pipeline must exceed the critical speed:

$$
v_{m}>v_{c r} .
$$

If $v_{m}<v_{c r}$ is valid, it is necessary to take another value of the pipelines diameter and do a recalculation.

The equivalent length of the pipeline:

$$
L_{\mathrm{f}}=L+H+L_{e q . e l}+L_{e q . s h},
$$

where $L_{\text {eq.el }}$ - length equivalent to the number of ells (Table 1); $L_{\text {eq.sh }}$ - length equivalent to double-sided shutters (two-way switch is equivalent to a pipeline of $8 \mathrm{~m}$ in length).

The transverse section of the pipeline:

$$
A=\frac{\pi d_{p}^{2}}{4} .
$$

Table 1. The length of the pipelines, equivalent to the ells.

\begin{tabular}{|l|c|c|c|c|}
\hline \multirow{2}{*}{ Bulk cargo } & \multicolumn{4}{c|}{ Value $L_{\text {eq.el }}, \mathrm{m}$, in relation to $R_{e l} / d_{p}$} \\
\cline { 2 - 5 } & 4 & 6 & 10 & 20 \\
\hline Dusty & $4 \ldots 8$ & $5 \ldots 10$ & $6 \ldots 10$ & $8 \ldots 10$ \\
\hline Grain homogeneous & - & $8 \ldots 10$ & $12 \ldots 16$ & $16 \ldots 20$ \\
\hline Small-necked heterogeneous & - & - & $28 \ldots 35$ & $33 \ldots 45$ \\
\hline $\begin{array}{l}\text { The gluttonous is not } \\
\text { homogeneous }\end{array}$ & - & - & $60 \ldots 80$ & $70 \ldots 90$ \\
\hline
\end{tabular}

Note. $R_{e l}$ - radius of curvature, $d_{p}$ - inner diameter of the pipe.

The pressure losses in the pipeline in the case of clean air (isothermal air flow at pressure differences not exceeding $9.81 \cdot 10^{4} \mathrm{~Pa}$ ):

$$
p_{0}=\sqrt{\frac{T_{a}^{2} g R T \lambda L_{f}}{A^{2} d_{p}}+p_{e}^{2}}-9.81 \cdot 10^{4},
$$

where $R=29.3$ - universal gas constant; $T=283^{\circ} \mathrm{C}$ - absolute temperature of the environment; $\lambda=0.016 \ldots 0.02 ; 0.015 \ldots 0.018 ; 0.014 \ldots 0.016$ - coefficient of resistance respectively for new and crowned pipes with diameters $d_{p}=150 ; 175 ; 200 \mathrm{~mm} ; p_{e}=10.3 \cdot 10^{4} \mathrm{~Pa}$ - pressure at the end of the pipeline.

The losses of pressure in a pipeline of equivalent length $L_{\mathrm{f}}$, taking into account rectilinear areas, rounding and two-way shutters: 


$$
p_{n}=p_{0}\left(1+n_{3} \mu \frac{a g d_{p}}{v_{m}^{2}}\right)
$$

where $n_{3}=0.1 \ldots 0.075-$ the experimental constant.

The dynamic pressure losses:

$$
p_{d}=\frac{v_{m}^{2}}{2} \rho_{a}(1+\beta \mu),
$$

where $\beta=0.35 \ldots 0.85-$ an indicator of the relative velocity of the materials particles, $\beta=0.6 \ldots 0.85$ - for dusty cargoes.

The losses of pressure in short vertical pipelines:

$$
p_{v}=(1+\mu) \rho_{a} H g \text {. }
$$

The losses of pressure in the feeders without a dosage device are equivalent to $90^{\circ}$ rounding lengths $p_{Z}=(1.96 \ldots 2.94) \cdot 10^{4} \mathrm{~Pa}$. Consequently, we accept $p_{Z}=2.45 \cdot 10^{4} \mathrm{~Pa}$.

The total pressure losses in the pneumatic system:

$$
p_{t}=p_{n}+p_{d}+p_{v}+p_{z} .
$$

The air flow at the outlet of the blower machine:

$$
V_{t}=(1.1 \ldots 1.15) V_{a}
$$

The end pressure in the pipeline:

$$
p_{e}=p_{t}+p
$$

where $p=9.81 \cdot 10^{4} \mathrm{~Pa}-$ the atmospheric pressure.

The work of the blower machine assigned to $1 \mathrm{~m}^{3}$ of suction air by the isothermal pressure:

$$
A_{m}=225900 \cdot \lg \frac{p_{e}}{p}
$$

The power of the electric motor of the blower machine:

$$
P=\frac{k \cdot A_{m} \cdot V_{t}}{10^{3} \cdot \eta},
$$

where $k=1.1$ - the reserve coefficient; $\eta=0.75$ - coefficient of machine efficiency.

In order to construct the analytical dependence of the drive power of the blower unit on the design data of the transport unit, we will make some algebraic transformations.

Substituting (2) into (3), we have:

$$
V=1000 T_{c}\left(\frac{1}{\rho_{c}}+\frac{1}{\mu \rho_{a}}\right) .
$$

Substituting (18) into (6), we have: 


$$
v_{m}=\frac{T_{c}\left(\rho_{c}+\mu \rho_{a}\right)}{0.9 \pi d_{p}^{2} \rho_{c} \mu \rho_{a}}
$$

For further studies, we denote $L_{e q . e l}=\gamma$ and $L_{e q . s h}=\varepsilon$, where $\gamma$ and $\varepsilon-$ the corresponding values in table 1 .

Substituting (1), (7), (8) into (9), we have:

$$
p_{0}=\sqrt{\frac{T_{c}^{2} g R T \lambda(L+H+\gamma+\varepsilon)}{0.81 \mu^{2} \pi^{2} d_{p}^{5}}+p_{e}^{2}}-9.81 \cdot 10^{4}
$$

Substituting (19) and (20) into (10), we have:

$$
p_{n}=\left(\sqrt{\frac{T_{c}^{2} g R T \lambda(L+H+\gamma+\varepsilon)}{0.81 \mu^{2} \pi^{2} d_{p}^{5}}+p_{e}^{2}}-9.81 \cdot 10^{4}\right)\left(1+n_{3} \mu^{3} \frac{0.81 a g d_{p}^{5} \pi^{2} \rho_{a}^{2} \rho_{c}^{2}}{T_{c}^{2}\left(\rho_{c}+\mu \rho_{a}\right)^{2}}\right)
$$

Substituting (19) into (11), we have:

$$
p_{d}=\frac{T_{c}^{2}\left(\rho_{c}+\mu \rho_{a}\right)^{2}}{1.8 \pi^{2} d_{p}^{4} \rho_{c}^{2} \mu^{2} \rho_{a}^{2}} \rho_{a}(1+\beta \mu)
$$

Substituting (12), (21), (22) into (13), we have:

$$
\begin{gathered}
p_{t}=\left(\sqrt{\frac{T_{c}^{2} g R T \lambda(L+H+\gamma+\varepsilon)}{0.81 \mu^{2} \pi^{2} d_{p}^{5}}+p_{e}^{2}}-9.81 \cdot 10^{4}\right)\left(1+n_{3} \mu^{3} \frac{0.81 a g d_{p}^{5} \pi^{2} \rho_{a}^{2} \rho_{c}^{2}}{T_{c}^{2}\left(\rho_{c}+\mu \rho_{a}\right)^{2}}\right)+ \\
+\frac{T_{c}^{2}\left(\rho_{c}+\mu \rho_{a}\right)^{2}}{1.8 \pi^{2} d_{p}^{4} \rho_{c}^{2} \mu^{2} \rho_{a}}(1+\beta \mu)+(1+\mu) \rho_{a} H g+p_{z} .
\end{gathered}
$$

Substituting (2) into (14), we have:

$$
V_{t}=\frac{0.32 T_{c}}{\mu \rho_{a}}
$$

We convert (17) and substitute (24), (16), (23) into (17), we have:

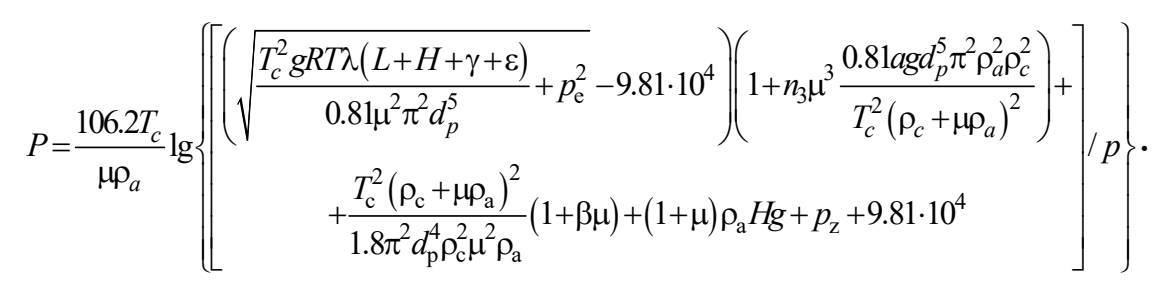

For the graphical analysis of the dependence of the compressor drive power of the pneumatic transport unit, we accept: cargo - cement $\rho_{c}=2600 \mathrm{~kg} / \mathrm{m}^{3}$; horizontal and 
vertical dimensions of the transportation route $-L=200 \mathrm{~m}$ and $H=18 \mathrm{~m}$; air density $\rho_{a}=1.2 \mathrm{~kg} / \mathrm{m}^{3}$; a track with three-ell by the angle $90^{\circ}$ and two double-sided shutters, that is, according to table $1 \gamma=30 \mathrm{~m}$ and $\varepsilon=16 \mathrm{~m}$.

By the given initial data, the dependence of the compressor drive power on the load productivity and the coefficient of the mixture concentration for systems with high vacuum and systems of various pressures are shown in Fig. 2.

a)

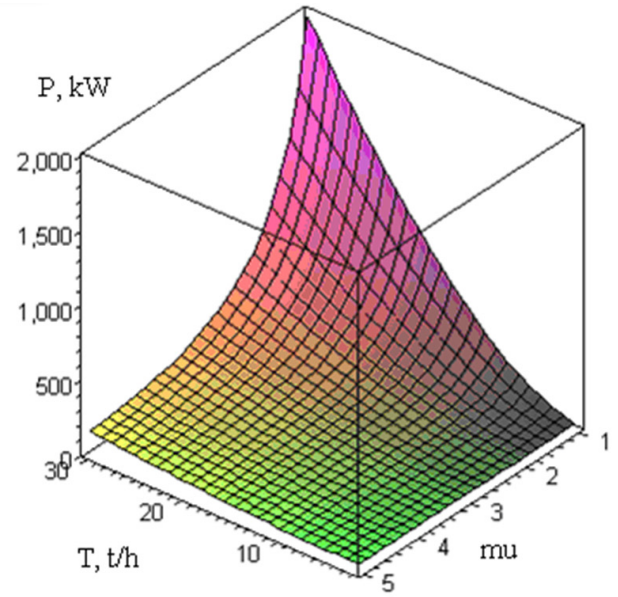

b)

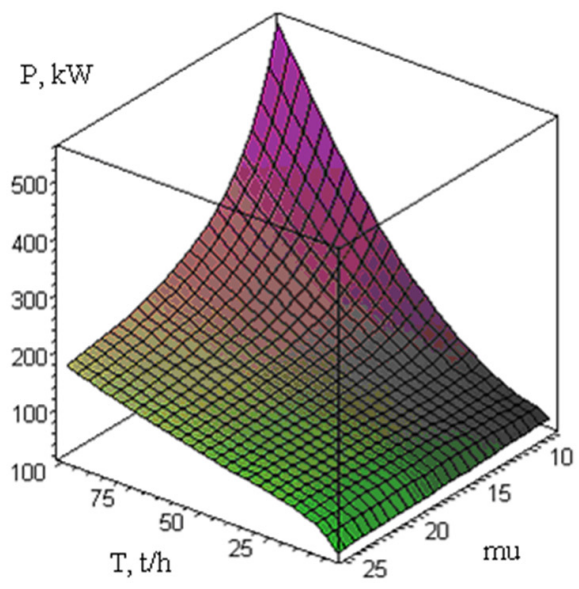

Fig. 2. Graphic dependence of the power of the electric motor of the blower machine on the productivity and coefficient of the mixture concentration: a) - machines with high vacuum by $T_{c}=2 \ldots 30 \mathrm{t} / \mathrm{h}$ and $\left.\mu=1 \ldots 5 ; \mathrm{b}\right)$ - machines with different pressure by $T_{c}=2 \ldots 100 \mathrm{t} / \mathrm{h}$ and $\mu=8 . .25$

In order to construct graphical dependence of the compressor drives power on the length of transportation we accept: $T_{c}=30 \mathrm{t} / \mathrm{h}$. The graphic dependences constructed for the systems with high vacuum $\mu=5$ and systems with different pressures $\mu=25$ are shown in Fig. 3.
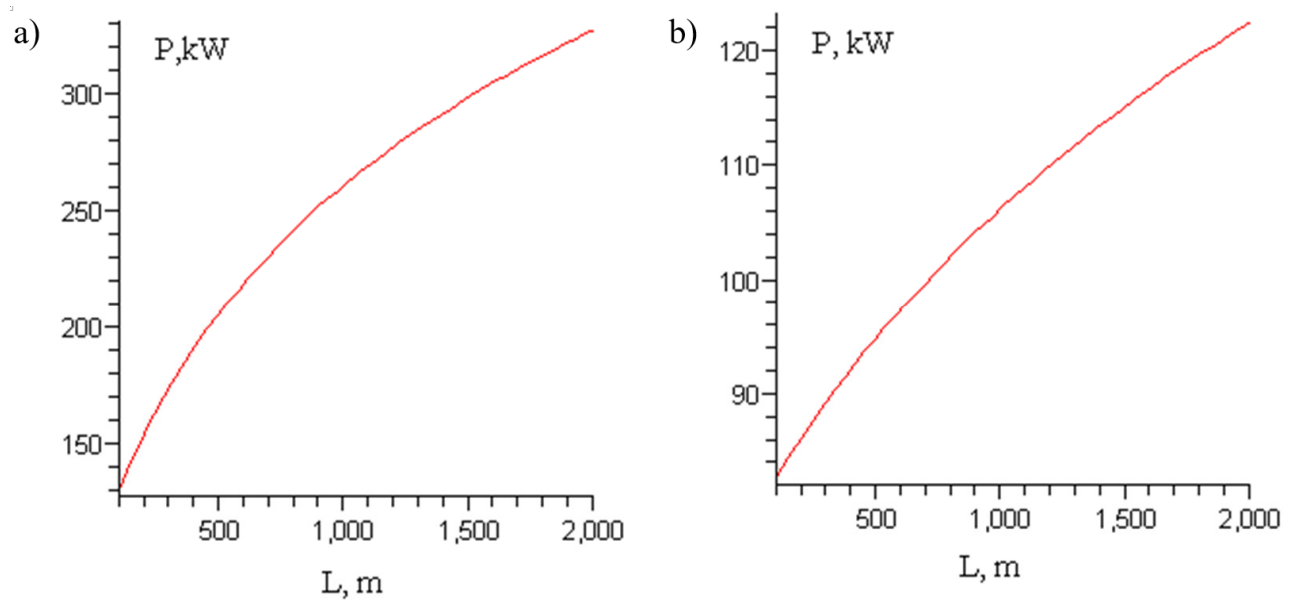

Fig. 3. Graphic dependence of the power of the electric motor of the blower machine on the transportation length: a) - machines with high vacuum by $T_{c}=2 \ldots 30 \mathrm{t} / \mathrm{h}$ and $\mu=5 ; \mathrm{b}$ ) - machines with different pressure by $T_{c}=2 \ldots 30 \mathrm{t} / \mathrm{h}$ and $\mu=25$ 


\section{Conclusions from research and prospects, further development in this direction}

The analysis of the dependence of all elements of the calculation, given in [2], on the initial parameters for designing has been carried out for pneumatic conveyors. The analytical dependence of the compressor drives power on the loads density, the coefficient of the mixtures concentration, the productivity, the geometric dimensions of the route, the number and types of auxiliary devices have been constructed. Involving the constructed analytical dependencies, a graphical analysis of the change in the value of the compressor drive power during the variation of the design parameters values of the pneumatic machines was carried out. The analysis showed that the compressor drives power with the growth of the coefficient of the mixture concentration decreases, with increasing productivity - increases, with increasing length of transportation - increases. With the same output data, the compressor power of the systems with high vacuum is greater than the systems of different pressures. Further research is needed in the direction of developing an algorithm for optimizing energy consumption of pneumatic transport systems taking into considering the constructed dependencies.

\section{References}

1. N.E. Romakyn, Mashyny nepreryvnoho transporta (Akademiya, Moscow, 2008)

2. V.S. Bondaryev, O.I. Dubinets, M.P. Kolisnyk ta insh. Pidyomno-transportni mashyny: rozrakhunky pidnimalnykh ta transportnykh mashyn (Vyshcha shkola, Kyiv, 2009)

3. B.L. Vyshnya, B.S. Drozdov, V.T. Stefanenko. Pnevmotransport. Raschoty, skhemy, oborudovanye (Socrat, Yekaterinburg, 2010)

4. F.K. Ivanchenko Pod'yemno-transportnyye mashiny (Vyshcha shkola, Kyiv, 1993)

5. A.I. Voloshin, B.V. Ponomarev. Mekhanika pnevmotransportirovaniya sypuchikh materialov (Naukova dumka, Kyiv, 2001)

6. S.L. Litvinenko, G.I. Nesterenko ta insh. Mekhanizatsiya $i$ avtomatizatsiya pogruzochno - razgruzochnykh rabot (Kondor, Kyiv, 2016)

7. N.N. Koval'nogov, A.S. Rtishcheva. Raschet techeniya i soprotivleniya treniya potoka $v$ soplakh Lavalya (ULGTU, Ulyanovsk, 2007)

8. A.I. Baryshev, V.A. Budishevskiy, A.A. Sulima ta insh. Raschet i proyektirovaniye transportnykh sredstv nepreryvnogo deystviya (Nord-Press, Donetsk, 2005)

9. V.M. Bohomas, M.V. Borenko, S.V. Patsanovskyy, O.O. Tkachov, Nauka i prohres transportu 6, 136-157 (2016)

10. V.M. Bohomas, Nauka i prohres transportu 1, 131-146 (2016) 